\title{
ARTHUR DE SALLES: UM TROVADOR MEDIEVAL?
}

Alicia Duhá Lose*

\section{Arthur de Salles: o homem e o poeta}

Q

oteropolitano, Arthur de Salles, que viveu entre 1879 e 1952, escreveu tanto em prosa quanto em verso, transitou entre o Parnasianismo e o Simbolismo e pode ser considerado um dos representantes da fase de transição pré-modernista. Membro da Academia de Letras da Bahia, Arthur de Salles ocupava a cadeira de $n^{\circ} 3$.

Publicou em vida apenas 4 obras completas (Poesias, 1920; Sangue Máo, 1928; Poemas Regionais, 1948 e a tradução de Macbeth, de Shakespeare, com um ensaio que se constitui no Prefácio do volume 10 da coleção Clássicos Jackson). Sua "Obra Dispersa", no entanto, assume proporções bem maiores. Até o momento, o Grupo de Edição Crítica de Textos da UFBA, que se ocupa do Acervo do autor, pôde confirmar a publicação de 24 títulos em jornais e 85 títulos em revistas.

A importância de Arthur de Salles também pode ser constatada pelos resultados preliminares das pesquisas que tiveram por base a Fortuna Crítica do Bahia.

* Programa de Pós-Graduação em Letras e Lingüística - Universidade Federal da 
poeta. ${ }^{1}$ Quando da sua morte, os jornais da capital e do interior do estado trouxeram cerca de 50 notícias, ao longo das quais estão contidos muitos textos de exaltação, consternação e apologia à vastíssima cultura do poeta.

Arthur de Salles era um homem querido e um intelectual admirado. Era, nos círculos artísticos, literários e sociais, pessoa das mais estimadas, quer pela formação intelectual que o distinguia, quer pela simplicidade de seus costumes. Todos o queriam e admiravam, considerando-o um mestre. Prova disso foi a grande comoção causada pela sua morte, desencadeando uma série de homenagens e solenidades em prol de sua memória, promovidas por diversas associações culturais e autoridades civis e militares. Seu enterro, que correu às expensas do Estado, "numa última homenagem àquele que tantos serviços prestou à nossa cultura", segundo afirmou o Diario da Bahia, ${ }^{2}$ foi acompanhado por grandes nomes da intelectualidade e da comunidade local.

Meio século passado e Arthur de Salles continua a constar das antologias e coletâneas literárias nacionais e internacionais, como se pode verificar em História da literatura brasileira, de Massuad Moisés, ${ }^{3}$ na obra homônima de Luciana Stegagno Picchio, traduzida para o Brasil e publicada em $1997,{ }^{4}$ na obra organizada por Cassiana Lacerda Carolo, Decadismo e simbolismo no Brasil: crítica e poética, publicada em $1980,{ }^{5}$ na antologia, $A$ Poesia baiana no século $X X$, organizada por Assis Brasil, ${ }^{6}$ e em tantos outros trabalhos que se ocupam da literatura brasileira.

Com frequiência, também, Arthur de Salles é lembrado e citado por intelectuais e artistas da sua terra natal em artigos e entrevistas. Aldamir da Cunha Miranda; em artigo publicado em maio de 2001, no jornal $A$ Tarde, de Salvador cujo título é "O poeta Artur de Sales" - afirma que a lembrança de sua presença

1 Cf. LOSE, A. D. Arthur de Salles: a edição de outros escritos. Salvador, 2001. 267f. + anexos + CD. Dissertação (Mestrado em Letras e Lingüística) - Programa de PósGraduação em Letras e Linguística da Universidade Federal da Bahia.

2 MORRE o maior poeta da Bahia. Diario da Bahia, Salvador, 28 jun. 1952. p. 1 e 4.

3 Cf. MOISÉS, M. História da literatura brasileira: simbolismo. São Paulo: Cultrix/ Edusp, 1985. p. 264.

4 Cf. STEGAGNO PICCHIO, L. História da literatura brasileira. Trad. Pérola de Carvalho e Alice Kyoko. Rio de Janeiro: Nova Aguilar, 1997. p. 352.

5 Cf. CAROLLO, C. L. (Org.). Decadismo e simbolismo no Brasil: crítica e poética. Rio de Janeiro: Livros Técnicos e Cientf́ficos 1980. p. 285-95. Sel. e apres. de Cassiana Lacerda Carollo.

6 Cf. BRASIL, A. (Org.). A poesia baiana no século XX: antologia. Rio de Janeiro: Imago, 1999. p. 44-47. Org., introd. e notas de Assis Brasil. 
e a sua obra ficaram marcados na memória das gerações subseqüentes. ${ }^{7}$ Referência a ele também faz Caetano Veloso em uma entrevista concedida a revista Cult, em agosto de 2001, na qual cita um trecho, que conhece de cor, do poema "Lúcia" de Arthur de Salles, de quem, segundo ele, seu pai era grande admirador. $^{8}$

Foi Caetano Veloso também quem gravou o Hino do Senhor do Bonfim, cuja letra é de Arthur de Salles. O Hino é cantado pelo povo baiano todos os anos na Festa em homenagem ao santo de maior devoção na Bahia. Sua popularidade é tanta que chega a ser executado, também, inúmeras vezes, pelos músicos dos trios elétricos no carnaval baiano.

\section{O acervo}

Em vista da dimensão da obra deixada pelo poeta baiano, o Setor de Filologia Românica do Instituto de Letras da Universidade Federal da Bahia empenhou-se em organizar a Coleção Arthur de Salles, o que foi feito em 1977. Desde então, o Grupo de Edição Crítica de Textos da UFBA vem se ocupando do resgate de informações sobre a vida e a obra do citado poeta. A Coleção Arthur de Salles se encontra arquivada, atualmente, em três diferentes acervos: o Acervo Hélio Simões, o da Academia de Letras da Bahia, e o do Setor de Filologia Românica do Instituto de Letras da UFBA, o mais relevante deles, por possuir documentos pertencentes à família do Poeta. ${ }^{9}$

Os documentos da Coleção que se encontram na UFBA foram divididos em categorias de acordo com as suas características extrínsecas e intrínsecas, constituindo-se de: manuscritos (autógrafos ou apógrafos, que ainda podem ser anotações ou esboços, rascunhos, borrões passados a limpo, texto definitivo e ainda o epistolário do autor); datiloscritos (com emendas autógrafas ou não) e impressos. Ainda compõem o acervo, exemplares de todas as teses, dissertações e trabalhos gerados pelo grupo de Edição Crítica da "Obra" de Arthur de Salles, além de elementos relativos à biografia do autor - fotografias,

7 MIRANDA, A. da C. O poeta Artur de Sales. A Tarde. Salvador, 19 maio 2001. Caderno Cultural, p. 3.

8 ADRIANO, C.; VOROBOW, R. Outras palavras. Entrevista com Caetano Veloso. Cult Revista brasileira de literatura, São Paulo, ago. 2001. p. 42-43.

9 GAMA, A. R. da; MARQUES TELLES, C. Os rascunhos e as anotações de Arthur de Salles. In: ENCONTRO INTERNACIONAL DE PESQUISADORES DO MANUSCRITO E DE EDIÇÕES, 4., 1994, São Paulo. Anais... São Paulo: USP, 1994. p. 95. 
entrevistas realizadas com seus familiares e amigos, depoimentos - e documentos pertencentes à sua fortuna crítica.

\section{Um poema à moda medieval}

Entre os documentos da pasta 001 da Coleção Arthur de Salles, do Setor de Filologia Românica da UFBA, existem dois que chamam rapidamente a atenção do pesquisador. Trata-se de dois testemunhos de um mesmo poema, catalogados sob os números 001:0009 e 001:0007, de forma inversa à ordem cronológica.

O primeiro (001:0009) é um documento autógrafo, manuscrito em papel almaço, com alguns rasgos nas bordas. Na parte superior da folha, ao centro, vêse o título Catalectos, sublinhado, e logo abaixo três estrofes de 6 versos octassílabos. A escrita é clara e pausada, dando ao documento características de um texto passado a limpo. Encontra-se apenas uma rasura, causada provavelmente por excesso de tinta, não por vacilação do autor. Seguido à última estrofe, nota-se um sinal em forma de cruz, indicativo de final.

O segundo documento (001:0007), em papel de carta, também é manuscrito, apógrafo, com letra de Maria das Dores Salles Brasil, prima do poeta que fazia às vezes de sua secretária. $O$ poema, assim como o anterior, é distribuído em 3 estrofes de 6 versos. A escrita também é clara e pausada, ou seja, trata-se também de um texto passado a limpo. No entanto, embora o manuscrito seja apógrafo, o testemunho é autógrafo, em virtude das emendas autorais feitas no texto, onde podem ser apuradas algumas divergências, a começar pelo título que, de Catalectos, como no testemunho anterior, passa a ser Rimas Várias. ${ }^{10}$

Todavia, todas as alterações servem a um objetivo muito claro seguido pelo poeta. Arthur de Salles tencionava criar um poema nos moldes dos Trovadores Medievais, o que fica evidente após uma análise mais apurada da estrutura e do vocabulário de ambos os testemunhos. Por exemplo: 1) ao substituir $m$ por $n$ em final de palavras, em bem $\rightarrow$ ben, deixa a grafia mais próxima da forma medieval; 2) quando substitui $D e$ vós $\rightarrow$ Por vós, força a repetição da expressão, já que essa mesma estrutura vai se repetir na estrofe seguinte, para forçar o efeito de dobre, do qual, mais tarde, ele se desfaz; 3) quando troca o $l$ por $n \mathrm{em}$ deslembra $\rightarrow$ Desnembra ou alembra $\rightarrow$ nembra aproxima a palavra de sua forma

10 Muitas vezes, na busca pela forma, o autor termina por endurecer o texto, tornando-o, no entanto, formalmente mais perfeito. 
antiga; 4) quando substitui sucessivamente $\operatorname{sem}$ razão $\rightarrow a$ desrazão $\rightarrow$ toda cuidação, mostra o apuro das estruturas usadas no medievo; 5) assim como quando suprime o $h$ em havedes $\rightarrow$ avedes; 6) e substitui $o$ por $e$ em nom $\rightarrow$ nem; 7) ou muda a pessoa verbal de ser para obter o y em será $\rightarrow$ serey.

\section{Uma cantiga de amor}

Arthur de Salles, como foi testemunhado inúmeras vezes por críticos e admiradores, era um grande intelectual, amante das letras e da literatura. Segundo Alberto Silva, Arthur de Salles era

...sem contestação o nosso maior poeta contemporâneo, (...) a nossa mais sólida e mais profunda cultura literária. (...) Representou, em nossa época e em nossa terra, a mais perfeita cultura literária nacional e estrangeira, particularmente a portuguesa, a inglesa, a francesa, a alemã, a italiana, a espanhola e a escandinava. Foi, evidentemente, depois de Castro Alves, o poeta mais fecundo e mais brilhante que a Bahia já possuiu. Guloso de tudo aprender nos domínios da poética e da Literatura, Artur de Sales era um ledor inveterado: leu muito, muitíssimo. (...) Mestre insigne, conhecedor abalisado da História..."

Para Tomé de Souza, Arthur de Salles era homem "possuidor de um espírito fecundo, e de vasta cultura (...) patrimônio inestimável dessa inteligência, dessa cultura". ${ }^{12} \mathrm{E}$ foi, certamente, lançando mão dessa cultura e desse saber que Arthur de Salles escreveu, em pleno século $\mathrm{XX}$, um poema nos moldes das cantigas medievais, seguindo-lhes tanto a estrutura métrica e rítmica como o vocabulário, sobremaneira elaborado. Rimas Várias é uma cantiga de amor, onde é o homem que fala, expondo a dor dos seus sentimentos causada pelo amor não correspondido. ${ }^{13}$

11 SILVA, A. Artur de Sales. A Tarde, Salvador, [19-]. p. 3.

12 SOUZA, T de. Artur de Sales. Diario da Bahia, Salvador, [19-]. p. 5.

13 SPINA, S. A lírica trovadoresca. 2. ed. São Paulo: Grifo, 1972. p. 296. 
Conforme comunicação apresentada na XVIII Jornada de Estudos Linguísticos do GELNE, ${ }^{14}$ a leitura dos dois manuscritos mostra os seguintes movimentos de correção. ${ }^{15}$

001:0007

$<$ Catalectos $>$ [-Rimas varias $]$
001:0009

Cataletos

\section{Restos de uma novella perdida}

Por vós ey tido e ey provado

Por vos amar tanta provança.....

Nunca de vós não ouve grado,

Nem ouve ben minha esperança.

Ay minha gran desaventura....

Coita de amor que sempre dura!.
Por vós ey tido e ey provado

Por vos amar tanta provança....

Nunca de vós não ouve grado.

Nem ouve de bem minha esperança...

Ay minha gran desaventura...

Coita de amor que sempre dura

$<$ Por vós $><$ d $>$ [D]esnembra <a desrazão $>$

De vós deslembra a sem razão

[-toda][ $\rightarrow$ cuidação]

$O$ coração que tudo nembra.

O coração que tudo alembra,

Por vós, que avedes dado em sembra

Males sem cont $<a>[0]$ ao coração....

De vós que havedes dado em sembra

Ay minha gran desventura

Coita de amor que sempre dura!

Males sem conto ao coração.

Ay minha gran desaventura

Coita de amor que sempre dura.

10

Não val meu pranto, ça sei ben

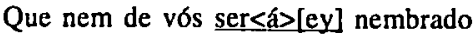

[ $\rightarrow$ serey]

Vou-me per hy com meu cuidado

15

Sen attender per nulla ren.

Ay minha gran desaventura...

20
Non val meu pranto ca sei ben

Que non de vós será nembrado

Voy-me por hy em meu cuydado

Sen attender per nulla ren

Ay minha gran desaventura

Coita de amor que sempre dura.

14 LINGÜÍSTICOS DO GELNE, 18., 2000, Salvador. Anais... Salvador: UFBA, 2000. No prelo.

15 Para a transcrição dos manuscritos foram usados os seguintes operadores: expurgos < >; emendas [ ]; emendas na entrelinha superior: -; emendas na margem direita: $\rightarrow$ 
Cotejando ambos os testemunhos, obtemos o que seria a versão definitiva dessa cantiga:

\section{Rimas Varias}

Restos de uma novella perdida

Coita de amor que sempre dura!.

Desnembra toda cuidação

O coração que tudo nembra.

Por voss, que avedes dado em sembra

10 Males sem conto ao coração....

Ay minha gran des[a]ventura

Coita de amor que sempre dura!

15

Não val meu pranto, ca sei bem Que nem de vós serey nembrado Vou-me per hy com meu cuidado Sen attender per nulla ren. Ay minha gran desaventura...

Coita de amor que sempre dura!.

\section{A estrutura das cantigas medievais em Rimas Várias}

Rimas Varias é um poema de 18 versos octassílabos - Por/ vos/ a/mar/ tan/ta/ pro/van//ça-, divididos em três estrofes $-1^{\mathbf{a}}$ Por vós $/ 2^{\mathrm{a}}$ Desnembra $/ 3^{\mathrm{a}}$ Não val -, com o acento recaindo na $2^{\mathrm{a}} \mathrm{e}$ na $8^{\mathrm{a}}$ sílabas - Por/vós/ ey/ti/do/ ef ey/ pro/val/do -, e rimas cruzadas e emparelhadas - ababcc, abbacc, abbacc , características que se encaixam, ao que parece, àquelas percebidas nas cantigas medievais. 


\section{Celso Cunha no Cancioneiro Paay Gômez Charinho diz que}

Muito freqüente na poesia narrativa e didática do norte e do sul da França, o octassílabo ${ }^{16}$ foi também um dos versos mais usados pelos trovadores galego-portuguêses, principalmente na cantiga de amor. D. Denis, por exemplo, dêle se utilizou em trinta e nove de suas cento e trinta e oito canções. (...) Quanto à acentuação, sabe-se que êste verso apresentava na lírica provençal, além do acento obrigatório na $8^{a}$, de regra, um outro secundário na $4^{a}$ silaba (...). Também nas cantigas galego-portuguêsas era essa a forma mais antiga e usual do octassilabo (...). Posteriormente, a par dêsse tipo, conheceu a lírica peninsular um octassíabo com a $3^{a}$ acentuada em lugar da $4^{a}$ (...) e outros menos freqüentes, em que o acento secundário recai na $2^{a}$ ou na $5^{a}$, ou nas duas simultaneamente. ${ }^{17}$

Segundo Amorim de Carvalho, no seu Tratado de Versificação Portuguesa, a poesia medieval portuguesa (séc. XII a XIV) tinha como elemento bem característico e freqüente o refrão. ${ }^{18}$ Para Celso Cunha "Tanto as cantigas de amor e de amigo como as de escárnio ou de mal-dizer podiam apresentar ou não estribilho. (...) As primeiras, de caráter popular por excelência, denominavam-se cantigas de refram", ${ }^{19}$ característica também presente em Rimas Várias, que ao final de cada estrofe repete o estribilho "Ay minha gran desaventura... / Coita de amor que sempre dura".

"A maioria dos trovadores portugueses não empregou mais de três rimas numa estrofe", ${ }^{20}$ afirma Celso Cunha. Seguindo essa estrutura, Rimas Várias apresenta na primeira estrofe a rima ababcc, na segunda e na terceira abbacc.

Arthur de Salles utilizou-se ainda do recurso do dobre - "a repetição da mesma palavra em lugares determinados das estrofes" ${ }^{21}$ - em seu primeiro teste-

16 Os grifos em itálico são nossos.

17 CUNHA, C. O cancioneiro de Paay Gômez Charinho, 1945. In: CUNHA, C. Cancioneiro dos trovadores do mar. Lisboa: Imprensa Nacional - Casa da Moeda, 1999. Ed. prep. por Elsa Gonçalves. p. 59.

18 CARVALHO, A. de. Tratado de versificação portuguesa. 2. ed. Lisboa: Portugália, 1965. p. 152.

19 CUNHA, O Cancioneiro de Paay..., op. cit., p. 74.

20 Ibid., p. 75.

21 Ibid., p. 86. 
munho (Catalectos, doc. 001:0009) quando repete, no primeiro verso da primeira e da segunda estrofes "Por vós", porém se desfaz desse recurso no segundo testemunho (Rimas Várias, doc. 001:0007), substituindo, na segunda estrofe, essa expressão por " $D e$ vós".

\section{Uma visita ao vocabulário medieval}

Celso Cunha, no Cancioneiro de Joan Zorro, afirma que "A linguagem poética é por natureza uma linguagem arcaica, porque repousa sôbre uma técnica e exige um aprendizado." 22 Ainda conforme Celso Cunha - "se a linguagem poética atual apresenta características arcaicas em relação à língua corrente, que dizer da trovadoresca, muito mais fixa e convencional?" 23

Reforçando essa idéia, não é apenas através da estrutura composicional que Arthur de Salles constrói, cuidadosamente, uma cantiga medieval. Em manuscrito sob o título de "Pequeno diccionario de palavras e fhrases" (017:0165; 017:0166; 017:0167), Arthur de Salles faz uma listagem de frases e palavras, acompanhadas de seus significados, onde podemos encontrar termos que fazem parte do vocabulário medieval - como meôgo, cho, chus - alguns deles serão utilizadas em Rimas Várias, como nembra e havedes. O poeta, um obcecado pela perfeição, um estudioso inveterado, procurou cumprir o seu objetivo complementando a estrutura de seu poema com um vocabulário arcaizante, fazendo uso de palavras e expressões presentes nos poemas contidos em diversos cancioneiros como, por exemplo, $O$ Cancioneiro da Ajuda, ${ }^{24}$ o Cancioneiro Paay Gômez Charinho, ${ }^{25}$ o Cancioneiro Joan Zorro, ${ }^{26}$ o Cancioneiro de Martin Codax, ${ }^{27}$ entre outros.

22 CUNHA, C. O Cancioneiro de Joan Zorro, 1949. In: CUNHA, C. Cancioneiro dos trovadores do mar. Lisboa: Imprensa Nacional - Casa da Moeda, 1999. Ed. prep. por Elsa Gonçalves. p. 214.

23 Ibid., p. 215.

24 VANCONCELOS, C. M. de. Glossário do Cancioneiro da Ajuda, 1904. In:

(Ed.). Cancioneiro da Ajuda. Lisboa: Imprensa Nacional - Casa da Moeda, 1990. v. 1.

25 CUNHA, O Cancioneiro de Paay..., op. cit.

26 CUNHA, O Cancioneiro de Joan ..., op. cit.

27 CUNHA, C. O Cancioneiro de Martin Codax, 1956. In: CUNHA, C. Cancioneiro dos trovadores do mar. Lisboa: Imprensa Nacional - Casa da Moeda, 1999. Ed. prep. por Elsa Gonçalves. 


\title{
Glossário de Rimas Várias ${ }^{28}$
}

\author{
attender: (v. 16) vb., estar à espera \\ ben: (v.4) s.m., favor, mercê \\ $c a:$ (v. 13) conj. expl., pois \\ catalectos: s.m, coisas escolhidas \\ Coita: (v. 6,12, 18) s.f., pena, mágoa \\ cuidação: (v. 7) s.f., aflição \\ cuidado: (v. 15) s.m., preocupação, pensamento \\ desaventura: (v. 5, 11, 17) má-sorte, desfortúnio \\ Desnembra: (v. 7) vb. [desnembrar] esquecer \\ grado: (v. 3) s.m., vontade, agrado \\ gran: grão, grande \\ hy: (v. 15) adv., aí \\ Males: (v. 10) s.m., [mal] pesar, aflição \\ nembra: (v. 8) vb., [nembrar] lembrar, trazer à memória, fazer recordar \\ nembrado: (v. 14) s.m., lembrado \\ nulla ren: (v. 16) absolutamente nada \\ per: (v. 15) prep., através de, por meio de \\ provança: (v.2) s.f., superação de obstáculos \\ val: (v. 13) vb., [valer] servir
}

28 Para a construção desse Glossário foram usadas as seguintes obras: BLASCO, P. Les Chansons de Pero Garcia Burgalês. Paris: Fondation Calouste Gulbenkian/Centre Culturel Portugais, 1984; CUNHA, A. G. da. Dicionário etimológico Nova Fronteira da Língua Portuguesa. Rio de Janeiro: Nova Fronteira, 1982; CUNHA, A. G. da. Indice do Vocabulário do Português Medieval. Rio de Janeiro: Fundação Casa de Rui Barbosa, 1986. v. 1; CUNHA, A. G. da. Indice do Vocabulário do Português Medieval. Rio de Janeiro: Fundação Casa de Rui Barbosa, 1988. v. 2; CUNHA, A. G. da. Indice do Vocabulário do Português Medieval. Rio de Janeiro: Fundação Casa de Rui Barbosa, 1994. v. 3; FERREIRO, M. As cantigas de Rodrigu'Eanes de Vasconcelos. Santiago de Compostela: Laiovento, 1992; HUBER, J. Gramática do Portugués Antigo. Trad. de Maria Manuela Gouveia Delille. Lisboa: Fundação Calouste Gulbenkian, 1986; RODRÍGUEZ, J. L. El cancioneiro de Joan Airas de Santiago. Verba - Anuario Galego de Filoloxia, Santiago de Compostela, v. 12, 1980; VANCONCELOS, op. cit. 


\section{Arthur de Salles: um trovador medieval?}

Rimas Várias não é um fato isolado na obra de Arthur de Salles, não se trata apenas de um exercício de criação. Outro exemplo disso pode ser encontrado no seu poema dramático Sangue-Mau, ${ }^{29}$ que trata da questão do destino, onde a estrutura das cantigas de amor medievais torna a aparecer, na quarta parte do poema, a qual "refere-se ao amor não correspondido, que João Mareta, troveiro $^{30}$ infeliz, sente por Tereza." 31

No entanto, isso não faz do poeta um trovador medieval do século XX. Porque, Sangue-Mau, como afirma Nilton Vasco da Gama, "é um poema heterométrico e que apresenta uma grande variedade de rimas," 32 trazendo, ao lado dessa estrutura medieval, restrita apenas à quarta parte, ${ }^{33}$ vários outros tipos de versos.

Autor que transitou entre várias escolas literárias, aventurou-se tanto na poesia quanto na prosa, tendo êxito também na tradução, Arthur de Salles tem em trabalhos como esse um dos objetivos de seu projeto poético, um treinamento de criação, mas não sua "marca registrada".

\section{Considerações finais}

Arthur de Salles, nasceu para ser poeta e o foi até o final de sua vida. Ao longo das pesquisas biográficas realizadas até então, é difícil separar as características do poeta das do homem. No dizer de Antenor Coutinho "a poesia nele não era uma habilidade mental a ser exercitada nas horas vagas. A poesia foi seu sangue, sua alma, a razão inteira de sua existência. Ela o absorvia, o possuía integralmente." ${ }^{34} \mathrm{E}$ é graças a esses exercícios intelectuais do poeta e ao seu eruditismo que hoje temos em nossas mãos um quebra-cabeças como essas Rimas Várias. Escrito no século $\mathrm{XX}$, o poema, cautelosamente construído, reporta o pesquisador ao ambiente medieval do trovador frustrado em seu amor. $O$

29 SALLES, A. de. Sangue-Mau. Salvador: EDUFBA, 1981.339 p. Ed. crít. sob a dir. de Nilton Vasco da Gama.

30 Trovador (Grifo nosso).

31 SALLES, 1981, op. cit., p. 12.

32 Ibid., p. 18.

33 O poema é composto de um Prólogo e dez partes.

34 Antenor Coutinho, recorte de jornal sem indicações de periódico, data e página, pertencente à pasta 046 (Fortuna Crítica) do Acervo de Arthur de Salles. 
vocabulário, burilado e cuidadoso, dá margens ao estudo, deixando pistas dos passos seguidos pelo poeta em busca de suas fontes inspiradoras. Mas, infelizmente, dentre todos os manuscritos catalogados no Acervo, este trabalho, juntamente com a quarta parte de Sangue-Mau, parece ser único, em relação à literatura medieval. Outros há, no entanto, na mesma linha, tendo, porém, bases diversas, como é o exemplo de uma peça cujas personagens são Vulcano, $\mathrm{O}$ Poder, Prometheu, A Força e A Piedade..$^{35} \mathrm{O}$ texto, do qual apenas se possui um fragmento, em 2 fólios escritos no recto e no verso, reproduz a estrutura, o estilo e o vocabulário de uma "tragédia grega".

\section{RESUMO}

Em pleno século XX, Arthur de Salles, poeta baiano, usa de toda a sua cultura para escrever um poema nos moldes das cantigas trovadorescas do medievo. $O$ poeta, um obcecado pela perfeição, um estudioso inveterado, procurou cumprir o seu objetivo, complementando a estrutura de seu poema com um vocabulário arcaizante, fazendo uso de palavras e expressões presentes em diversos cancioneiros.

Palavra-chave: Arthur de Salles, poesia medieval, acervo literário.

\section{ABSTRACT}

In the 20th century, the Bahian poet Arthur de Salles uses all of his cultural background to write a poem in the same structure of medieval troubadour poems. The poet, a diligent scholar, attempted to attain his goal by adding an archaic vocabulary to the structure of his poem, using several words and expressions of many medieval ballads. Key-words: Arthur de Salles, medieval poetry, literary archive.

35 Manuscrito 003:0042. 


\section{REFERÊNCIAS}

ADRIANO, C.; VOROBOW, R. Outras palavras. Cult, São Paulo, p. 42-43, ago. 2001. Entrevista com Caetano Veloso.

BLASCO, P. Les Chansons de Pero Garcia Burgalês. Paris: Fondation Calouste Gulbenkian/Centre Culturel Portugais, 1984.

BRASIL, A. (Org.). A poesia baiana no século XX: antologia. Rio de Janeiro: Imago, 1999. p. 44-47.

CAROllo, C. L. (Org.). Decadismo e simbolismo no Brasil: crítica e poética. Rio de Janeiro: Livros Técnicos e Científicos, 1980. p. 285-295.

CARVALHO, A. de. Problemas da versificação. Lisboa: CLB, 1981.

CARVALHO, A. de. Tratado de versificação portuguesa. 2. ed. Lisboa: Portugália, 1965.

CUNHA, A. G. da. Dicionário etimológico Nova Fronteira da Língua Portuguesa. Rio de Janeiro: Nova Fronteira, 1982.

. Indice do Vocabulário do Português Medieval. Rio de Janeiro: Fundação Casa de Rui Barbosa, 1986. v. 1

. Indice do Vocabulário do Português Medieval. Rio de Janeiro: Fundação Casa de Rui Barbosa, 1988. v. 2.

. Indice do Vocabulário do Português Medieval. Rio de Janeiro: Fundação Casa de Rui Barbosa, 1994. v. 3.

CUNHA, C. Cancioneiro dos trovadores do mar. Lisboa: Imprensa Nacional - Casa da Moeda, 1999.

FERREIRO, M. As cantigas de Rodrigu'Eanes de Vasconcelos. Santiago de Compostela: Laiovento, 1992.

HUBER, J. Gramática do Português Antigo. Trad. de Maria Manuela Gouveia Delille. Lisboa: Fundação Calouste Gulbenkian, 1986.

LOSE, A. D. Arthur de Salles: a edição de outros escritos. Salvador, 2001. 267f. + anexos +CD. Dissertação (Mestrado em Letras e Lingüistica) - Programa de Pós-Graduação em Letras e Lingüística da Universidade Federal da Bahia. 
LOSE, A D. Sobre os manuscritos inéditos de Arthur de Salles. In: JORNADA DE ESTUDOS LINGÜÍSTICOS DO GELNE, 18., 2000, Salvador. Anais... Salvador: UFBA, 2000. No prelo.

MIRANDA, A. C. da. O poeta Artur de Sales. A Tarde, Salvador, 19 maio 2001. Caderno Cultural, p. 3.

MOISÉS, M. História da literatura brasileira: simbolismo. São Paulo: Cultrix/Edusp, 1985. p. 264.

MORRE o maior poeta da Bahia. Diario da Bahia, Salvador, 28 jun. 1952. p. 1 e 4.

PICCHIO, L. S. História da literatura brasileira. Trad.: Pérola de Carvalho e Alice Kyoko. Rio de Janeiro: Nova Aguilar, 1997. p. 352.

RODRÍGUEZ, J. L. El cancioneiro de Joan Airas de Santiago. Verba-Anuario Galego de Filoloxia, Santiago de Compostela, v. 12, 1980.

SALLES, A. de. Sangue-mau. Salvador: EDUFBA, 1981. 339 p.

SILVA, A. Artur de Sales. A Tarde, Salvador, [19-]. p. 3.

SOUZA, T. de. Arthur de Salles. Diario da Bahia, Salvador, [19-]. p. 5.

SPINA, S. A lírica trovadoresca. 2. ed. São Paulo: Grifo, 1972.

TAVANI, G. Ensaios Portugueses. Lisboa: Imprensa Nacional - Casa da Moeda, 1988.

VANCONCELOS, C. M. de. Glossário do Cancioneiro da Ajuda, 1904. In: (Ed.).

Cancioneiro da Ajuda. Lisboa: Imprensa Nacional - Casa da Moeda, 1990. v. 1. 